\title{
Estudio prospectivo de quistes de la lámina dental en neonatos venezolanos vih(+) y vih(-)
}

Rodríguez-C $\mathrm{C}^{1}$

Hernández-MdN ${ }^{2}$

Guerra-ME $E^{3}$

\section{Resumen}

Objetivo: Determinar la prevalencia de quistes de la lámina dental en un grupo de neonatos venezolanos VIH (+) y VIH (-) verticalmente expuestos. Materiales y métodos: Estudio prospectivo, analítico y descriptivo. Se recolectaron datos en neonatos VIH(+) y VIH (-) verticalmente expuestos. Fueron examinados clínicamente con la técnica rodilla a rodilla y con iluminación de la lámpara de la unidad dental. Se analizó la información general obtenida de las madres. El tratamiento de los datos se realizó mediante el Programa SPSS versión 11 de la escuela de Estadística y Actuario de la Facultad de Economía Universidad Central de Venezue- la. Resultados: La población estuvo conformada por 62 neonatos $32 \mathrm{VIH}(+)$ Y $30 \mathrm{VIH}(-)$. La ocupación de la madre en su mayoría eran amas de casa, $68 \%$ procedía de Caracas, 57\% pertenecían al género masculino, el motivo de consulta de los expuestos fue el control $72 \%$ y el de $\mathrm{VIH}(+)$ emergencias $88 \%$, el $83 \%$ presentaron quistes, con un predominio en el reborde maxilar. Conclusión: Los resultados obtenidos nos permiten destacar la importancia de la participación del odontopediatra dentro del equipo interdisciplinario que atiende a neonatos así como destacar la importancia del examen bucal del recién nacido.

Palabras clave: VIH, recién nacidos.

Original article

\section{Prospective study of cyst of the lamina dental in venezuelan neonatos hiv (+) and hiv (-)}

\begin{abstract}
Objective: to determine the prevalence of cysts of the dental lamina in a group of Venezuelans HIV $(+)$ and HIV vertically exposed. Materials and methods: Prospective, analytical and descriptive,

study collected data in neonates HIV (+) and HIV (-). They were examined oral clinical by knee to knee position, and dental unit lamp, analyzed general information's from they mothers. The processing data was analyzed using the program SPSS version 11 of the statistics and actuary

\footnotetext{
${ }^{1}$ Especialista en Odontología Infantil, profesora colaboradora Centro de Atención a Pacientes con Enfermedades Infecto contagiosas "Dra. Elsa La Corte "Facultad de Odontología Universidad Central de Venezuela (CAPEI/UCV)

${ }^{2}$ Profesora Agregada, Especialista en Odontología Infantil, Coordinadora del Centro de Diagnóstico Clínico Facultad Odontología Universidad Central de Venezuela

${ }^{3}$ Profesora Titular; Doctora En Ciencias Mención Salud Bucal Materno Infantil Coordinadora del Programa el Binomio Madre e Hijo VIH/SIDA. CAPEI/UCV.
} 
School of Faculty Economics Universidad Central de Venezuela. Results: The population was compouse of 62 children. Most mother's occupation was hausewives, 68\% came from Caracas, $57 \%$ belonged to the male gender, the reason for consultation HIV (+) 88\% emergency and HIV (-) $72 \%$ for control, $83 \%$ had cyst predominance in alveolar ridge. Conclusion: The results highlight the importance and participation of the pediatric dentist in the multidisciplinary team this take care of neonates and the importance of oral examine during the first days of live.

Key Words: HIV, newborns.

\section{Artigo Original}

\section{Estudo prospectivo dos cistos da lâmina dentária os recém-nascidos venezuelanos HIV (+) e HIV(-)}

\section{Resumo}

Objetivo: Determinar a prevalência de cistos da lâmina dentária em um grupo de recémnascidos venezuelanos HIV (+) e HIV (-) expostos verticalmente. Materiais e métodos: Estudo prospectivo, analítico e descritivo. Os dados foram coletados em recém-nascidos HIV (+) e HIV (-) expostos verticalmente. Eles foram examinados clinicamente na posição joelho-joelho com iluminação do equipo odontológico. Informações gerais foram obtidas através das mães e analisadas. Os dados foram consolidados e avaliados através do programa SPSS versão 11 da escola de Estadística y Actuario de la Facultad de Economía Universidad Central de Venezuela. Resultados: A população foi composta por 62 recém-nascidos, sendo $32 \mathrm{HIV} \mathrm{(+)} \mathrm{e} 30 \mathrm{VIH}(-)$. As mães eram na maioria donas de casa, $68 \%$ procediam de Caracas, 57\% dos recém-nascidos eram do gênero masculino, o motivo da consulta foi para controle em $72 \%$ do grupo HIV (-) e no grupo de HIV (+) 88\% foi emergência, $83 \%$ tinham cistos, com predomínio no arco superior. Conclusão: Os resultados obtidos nos permitem destacar a importância da participação do odontopediatra na equipe interdisciplinar que atende a recém-nascidos, bem como destacar a importância do exame bucal do recém-nascido.

Palavras-chave: HIV, recém-nascido.

\section{Introducción}

El estudio de los quistes de la lámina dental en el recién nacido ha sido un tema de gran controversia en los últimos años. Durante el año 2009 se observó un alta frecuencia de quistes de la lámina dental durante el examen clínico que estábamos realizando a los neonatos hijos de madres $\mathrm{VIH}(+)$, por lo que nos motivamos a estudiar la presencia de quistes de la lámina dental en recién nacidos $\mathrm{VIH}(+)$ y VIH(-) verticalmente expuestos, que acudieron al Centro de Atención a Pacientes con Enfermedades Infectocontagiosas "Dra. Elsa La Corte" de la Facultad de Odontología de la Universidad Central de Venezuela (CAPEI/UCV).

El VIH se trasmite por contacto sexual, transfusión de sangre, compartiendo agujas para uso de drogas intravenosas y verticalmente de madre a hijo. Durante el curso de la enfermedad, una de las manifestaciones presentadas por to- 
dos los pacientes VIH/SIDA son las bucales ${ }^{1}$, su importancia y frecuencia es conocida y reportada en la literatura extensamente de allí que, la presencia de ciertas manifestaciones bucales es considerada como un marcador de la evolución de la enfermedad $7,8,9,10,11,12,13,14,15,16$.

\section{Objetivo general}

Determinar la prevalencia de quistes de la lámina dental en un grupo de neonatos venezolanos $\mathrm{VIH}(+)$ y VIH(-) verticalmente expuestos.

\section{Bases teóricas}

\section{Neonato}

Un neonato o recién nacido es el periodo que va desde el momento del nacimiento hasta las cuatro semanas de edad o menos. Lo propio del período neonatal es la adaptación que exige el paso de la vida intrauterina a la extrauterina. Son múltiples los cambios que afectan al niño en esta etapa. La patología neonatal es, en general, un problema de adaptación en alguno de los sistemas del recién nacido ${ }^{7}$.

El cuidado de todo recién nacido comprende su evaluación al menos en cuatro etapas durante los primeros días de vida: al nacer, durante el periodo de transición (primeras horas de vida), al cumplir 24 horas y previo a ser dado de alta con su madre del hospital ${ }^{17}$.

El protocolo del CAPEI/UCV establece el examen bucal del neonato durante la primera semana de vida.

\section{Generalidades de los quistes orales}

Existen múltiples clasificaciones de las lesiones quísticas bucales, dependiendo estas de su ori- gen, etiología o localización. Sapp y cols. 1998 clasifican los quistes en odontógenos y embrionarios o no odontógenos ${ }^{18}$.

Los primeros derivan de las siguientes estructuras epiteliales:

- Restos de Malassez, son pequeños islotes y tiras de epitelio odontógeno que se encuentra en el ligamento periodontal. Representan restos de la vaina radicular de Hertwing, una estructura epitelial embrionaria que rodea a la raíz en desarrollo. Aunque los restos de Malassez están presentes a lo largo de toda la longitud de la raíz, son más abundantes en la región apical.

- Epitelio reducido del esmalte, designa la capa de epitelio que permanece alrededor de la corona del diente después de completarse la formación del esmalte. Esta capa de epitelio deriva de los componentes epiteliales especializados del órgano del esmalte (epitelio del esmalte interno, estrato intermedio, retículo estrellado y epitelio del esmalte externo), que fueron activos durante la amelogénesis (formación del esmalte) y se colapsan originando una fina membrana inactiva de dos o tres células de espesor. Además, el epitelio reducido del esmalte puede incluir una pequeña población de células derivadas de la lámina dental que estaban conectadas con el órgano del esmalte durante su formación. El epitelio reducido del esmalte es, por tanto, unas colecciones complejas de células post secretorias cuyas proporciones pueden diferir entre unos dientes y otros y entre individuos. Se desconoce actualmente si la composición celular del epitelio reducido del esmalta afecta el crecimiento potencial de quistes de dentición individuales. 
- Restos de la lámina dental (restos de Serres), es un filamento de epitelio embrionario que transporta al órgano dental a su destino en el interior de los maxilares fetales en desarrollo. Durante su periodo funcional, la lámina dental conecta el órgano del esmalte de desarrollo con la mucosa alveolar. En su periodo post-funcional, la lámina dental se desintegra formando una serie de pequeños islotes y filamentos de epitelio que se denominan residuos de la lámina dental. Estos residuos persisten hasta la edad adulta $\mathrm{y}$ pueden encontrarse en el tejido conjuntivo gingival y dentro del hueso alveolar subyacente.

\section{Generalidades sobre quistes en neonatos}

Algunos nombres son utilizados como la misma definición Quiste Gingival del recién nacido, Quistes de la Lámina Dental de Recién Nacido, Perlas de Epstein, Nódulos de Bohn, Glándulas Gingivales o Perlas de Serres, Microquistes Gingivales, Remanentes epiteliales del Folículo Dental, Órganos Abortivos del Esmalte, Quistes Mucosos, Glandulares, Generación Epitelial del Germen de Esmalte, Restos Epiteliales, Perlas Epiteliales, quistes Epiteliales y Quistes de Retención.

Los primeros en describir los quistes palatinos del neonato fueron Epstein (1880) como un tipo de quistes consistentes en pequeños nódulos localizados a lo largo de la línea media del rafe de la cavidad oral en recién nacidos y fue llamada enfermedad de Epstein, él describió sus lesiones que a manera de Perlas ubicadas a lo lago del rafe medio originados por remanentes epiteliales atrapados, en cambio al referirnos a nódulos de Bohn (1886) como quistes remanentes de mucosa glandular encontrados en la cresta de los rebordes maxilares y mandibulares, y de los bordes laterales del paladar ${ }^{8}$.

“Los rebordes alveolares de la mandíbula y del maxilar varían considerablemente en su apariencia. Frecuentemente ellos son delgados en los laterales, y el tejido membranoso que los recubre es frágil y se extiende muchas veces hasta $1 \mathrm{~mm}$. Hasta los tejidos firmes de los rebordes alveolares. Esto persiste solo por pocas semanas. Frecuentemente se encuentran perlas epiteliales o quistes de inclusiones blancos, firmes, pequeños sobre o cerca de los márgenes de las encías. Ellos persisten por algunas semanas o meses y luego se rompen. Son muchos más comunes las perlas epiteliales en el rafe de la boca, donde ellas ocurren con gran frecuencia. Allí se encuentran cuerpos blancos del tamaño de una cabeza del alfiler, en grupos, a los lados del rafe medio o en la unión del paladar duro y blando. Ellos persisten por pocas semanas. En estos sitios se les conoces como Perlas de Epstein o Nódulos de Bohn." 9

\section{Generalidades sobre quistes de lámina dental}

Denominados también como Quistes de los rebordes, Quistes Alveolares, Quistes Gingivales del Recién Nacido.

Es típicamente una lesión del recién nacido, localizado a veces bilateralmente o cuatrilateralmente en la mayoría de los casos sobre germen dentario en la zona del primer molar primario en niños pequeños ${ }^{10}$, Hooley $(1967)^{11}$ apunta que el Quiste del Recién Nacido es infrecuente en sitios de los quistes epiteliales y siendo estos a veces bilaterales.

Para Fromm (1967) concluyo de un estudio de 1.367 recién nacidos de menos de 48 horas de 
edad a los cuales se examinaron quistes de inclusión en cavidad bucal clínicamente visibles con una incidencia de $75,9 \%$, es decir, en 1.028 recién nacidos. El nombre de quistes de la lámina dental describe hallazgos a lo largo de la cresta de los rebordes, los cuales se originan de remanentes de la lámina dental, sin correlacionar el numero de quistes y tamaño del recién nacido $^{12}$.

Estos quistes de recién nacidos por lo común múltiples, tienen aparición, en la parte anterior de los maxilares de lactantes y niños ${ }^{9,12}$.

Los Quistes derivados de la Lámina Dental (en los rebordes alveolares exclusivamente), sin tomar como parámetros la posibilidad del origen de las glándulas salivales accesorias, inversamente de las opiniones de Sicher en 1966 y Fromm en 1967, y tomando en cuenta las opiniones de Mather/Swindler 1970 quienes no están muy convencidos de que los acinos y ductos tipos mucosos mostrados en sus microfotografías estén presentes. Aunque están completamente conscientes de la presencia de glándulas mucosas en el paladar y no se puede escatimar la posibilidad de que las glándulas mucosas de desarrollen ectópicamente en la vecindad de las crestas de rebordes dentales. Opinión que confirma la calificación de Shafer y col en 1984; Shafer y col en 1986 escogida por nosotros ${ }^{16,17}$.

Los quistes gingivales del recién nacido están localizados sobre la superficie de la encía o cerca de ella tiene su origen probablemente de los restos de la Lámina dental, pueden ocurrir tanto en encía libre o adherida o en la paila gingival y suelen tener $1 \mathrm{~mm}$ o menos de diámetro, revestidos de un epitelio escamoso estratificado y la mayoría de la veces llenos de capas concéntricas de queratina ${ }^{15}$.
En 1979 Sanders ${ }^{20}$ apunta que los Quistes de la Lámina dental, las Perlas de Epstein y Nódulos de Bohn son términos que son frecuentemente usados como sinónimos; no obstante existen reportadas diferencias en cuanto su localización y rasgos distintivos histológicas. Los quistes de la Lámina dental son placas blanquecinas de remanentes de la Lámina dental; generalmente ocurren en números de 2 ó 3 a lo largo de la mucosa alveolar en infantes, siendo más comunes en el arco maxilar. Raramente se requiere de tratamiento, hasta que estas lesiones se rompen espontáneamente o con la erupción de la dentición primaria ${ }^{20}$.

La opinión Uauy y col en 1980 sobre la localización de estos quistes en los rebordes alveolares derivan de la lámina dentaria. En recién nacidos vivos la frecuencia es mayor durante el periodo neonatal, pero son pocos usuales después de pocas semanas. En sus resultados de 92 casos maxilares superiores y 21 casos en maxilares inferiores. Siendo en este ultimo la zona más frecuente a nivel incisiva y canina ${ }^{21}$. Para ese mismo año Batsakis concluye de una manera general que el quiste gingival es más frecuente en niños que en adultos $^{22}$.

Los quistes palatinos en la línea media en fetos son considerados como un microqueratoquiste, originado de remanentes de restos epiteliales de los procesos palatinos durante la fusión en la vida fetal. En su estudio Moreillon \& Schroedre 1982, usando 55 cabezas de fetos entre 8 y 26 semanas de edad fetal. Los restos epiteliales en la línea media palatina se observaron entre la semana 8 y 12, estos restos estaban confinados al paladar duro pero eran completamente ausentes en paladar blando, con un pico de frecuencia entre la $10^{\mathrm{a}}$ y $11^{\mathrm{va}}$ semana fetal. En comparación los quistes de la Lámina dental, los quistes palatinos eran más grandes y más tempranos en 
formarse, diferenciándose en la queratinización de su pared. A demás, los quistes de la línea media palatina en fetos contienen un gran número de células anucleares, extremadamente planas semejando a una piscina. El examen en ambas regiones en los fetos humanos revela un material con casi $100 \%$ presente de desarrollo de microqueratoquistes, tanto gingivales como en la línea media palatina, que luego se demostró con nódulos blancos clínicamente en recién nacidos en las mismas zonas ${ }^{23}$.

En el 2001 Laskaris ${ }^{24}$ apunta sobre el quiste gingival del recién nacido que son quiste pequeños rellenos de queratina. Cuya etiología proviene de remanentes de la Lámina dental, con una incidencia muy común, exclusiva en neonatos, con localización usualmente en la mucosa alveolar del maxilar superior. Se caracterizan clínicamente por ser nódulos múltiples o solitarios, asintomáticos, blanquecinos, sobre el proceso alveolar aproximadamente $1-3 \mathrm{~mm}$ de diámetro. Los quistes involucionan espontáneamente en pocas semanas. No tienen tratamiento indicado ${ }^{24}$.

Al respecto se ha publicado sobre los quistes palatinos y alveolares del recién nacidos, esta especial forma de quistes odontogénico es encontrada en el $80 \%$ de los recién nacidos. Aunque el quiste gingival del neonato tiene apariencia de un quiste epidermoide, se origina de remanentes epiteliales de la lámina dental anidados profundamente durante el desarrollo del diente después del $4^{\circ}$ mes intra uterino. Hoy en día se intercambian los términos para ambos quistes palatinos y gingivales del neonato. Los quistes palatinos son usualmente un tanto más grandes $\mathrm{y}$ menos numerosos que los quistes gingivales de los procesos alveolares en neonatos, pero las dos entidades son clínicamente indistinguibles. Ambos tipos de quistes son tan superficiales que algunos pueden romperse mientras se examinan. No se requiere de tratamiento. Los quistes son muy superficiales y dentro de unas semanas derramando su contenido inocuo hacia los alrededores de la boca y faringe. La cubierta epitelial entonces se fusiona con la que cubre la mucosa y será parte de ella. Ocasionalmente, hay quistes más grandes o quistes situados mas profundamente en el estroma submucoso que permanecen hasta 6-8 meses antes de romperse ${ }^{25}$.

\section{Características del VIH}

EL VIH pertenece a la familia Retroviridae, y a la subfamilia de los lentivirus. Los dos virus que producen el sida son el VIH-1 y el VIH-2. El VIH-1 es más frecuente en el hemisferio occidental, en Europa, Asia y África central, del sur y oriental. El VIH-2 es el principal virus causante de sida de África occidental, a pesar de que allí muchas personas están infectadas con la especie VIH-1. ${ }^{26}$ VIH-1 es el más importante debido a su potencial patogénico mayor, reflejado en la rápida diseminación de su infección por todo el mundo. El VIH-1 infecta células CD4+ (que poseen el receptor de membrana CD4) del sistema inmune, conduciendo a una profunda depresión de la inmunidad natural. Sin embargo, este virus también puede infectar otras células, incluyendo células neuronales ${ }^{1,27}$.

\section{Vías de transmisión del VIH}

Están bien establecidas en la literatura ${ }^{1,26}$ :

- Parenteral: Se transmite por contacto de la sangre y los productos sanguíneos, de órganos donados y del semen. La transmisión por la sangre ocurre principalmente por la utilización de agujas, jeringas $\mathrm{u}$ otros instrumentos insuficientemente esterilizados 
que atraviesan la piel y por la transfusión de sangre infectada.

- Sexual: A través de cualquier tipo de relaciones sexuales bien sea homo o heterosexuales. La vía principal es la relación sexual sin protección entre hombre y mujer (heterosexual) o entre hombres (homosexual). No hay casos documentados de transmisión entre mujeres. ${ }^{27}$

- De madre a hijo o vertical: Por vía intrauterina, durante el parto o durante la lactancia. Una madre infectada puede transmitir el virus al feto o al lactante durante el embarazo, el parto o la lactancia. Esta vía de transmisión se llama de madre a hijo, o vertical.

\section{Materiales y métodos}

Después de la revisión de la literatura se encontró que existen numerosos estudios que aborden el tema, pero son muy pocos los que realizan una investigación odontológica en recién nacidos $\mathrm{VIH}(+)$ o expuestos a este virus, por lo que realizamos un estudio retrospectivo, analítico y descriptivo, ya que recolectamos una serie de datos obtenidos de la boca en neonatos $\mathrm{VIH}(+)$ y VIH (-) verticalmente expuestos.

Método de observación: A todos recién nacidos se les realizó un examen bucal sistemático y minucioso, para estudiar la cavidad bucal siguiendo el protocolo de CAPEI/UCV, estos fueron examinados clínicamente sentados con la técnica rodilla a rodilla y con iluminación de la lámpara de la unidad dental, examinando clínicamente los tejidos blandos y duros bucales, para especificar la presencia de quistes de la lámina dental del neonato, así como también realizamos un análisis de la información general obtenida de los representantes en relación al tipo de transmisión del VIH, enfermedades padecidas, medicamentos que fueron suministrados.

Investigación no experimental, de tipo transversal, por su dimensión temporal ya que la evaluación fue en un periodo concreto a un grupo de neonatos que asistieron al CAPEI/UCV durante los meses enero a diciembre 2009 a la consulta de niños VIH (+) y VIH (-) verticalmente expuestos.

La muestra se seleccionó invitando a todos los neonatos venezolanos recién nacidos $\mathrm{VIH}(+)$ y VIH (-) verticalmente expuestos que acudieron al Servicio Pediátrico de Enfermedades Infecciosas del Hospital Universitario de Caracas y fueron referidos al CAPEI/UCV a participar en el estudio y quedó constituida por sesenta y dos neonatos (62), treinta y dos (32) VIH/SIDA y treinta (30) VIH (-), todos nacidos de madres VIH (+) durante el año 2009.

Se elaboró un instrumento para la recolección de datos que constó de dos partes: un cuestionario destinado a los representantes para la obtención de datos personales, motivo de consulta, tipo de transmisión o exposición, enfermedades padecidas y una ficha de patología, para registro de las características bucales alteraciones del desarrollo dental.

Los datos fueron dispuestos sobre tablas de contingencia para realizar en función de la distribución Chi-cuadrado; y de riesgo de producto cruzado; para la comparación de medias de dos grupos independientes se analizó a través de la distribución $t$ de student. Para comparar la presencia de alteraciones del desarrollo en ambos grupos y controlando por el grupo se utilizó el modelo logístico; a saber:

$$
\operatorname{logit} E\left(y_{i}=1\right)=\beta_{0}+\beta_{1} V I H+\beta_{2} R N
$$

donde: 
$E\left(y_{\mathrm{i}}\right)=\operatorname{Pr}\left(\mathrm{y}_{\mathrm{i}}=1\right)$, siendo
SIDA $_{\mathrm{i}}=\left\{\begin{array}{l}1 \text { si el } \mathrm{i} \text { - ésimo niño es VIH+/SIDA } \\ 0 \text { si el } \mathrm{i} \text { - ésimo niño es negativo }\end{array}\right.$

Edad: edad del niño en días siendo:

El tratamiento de los datos se realizó mediante el Programa SPSS versión 11 de la Escuela de Estadística y Actuario de la Facultad de Economía Universidad Central de Venezuela.

\section{Resultados}

Se estudiaron 62 neonatos que acudieron al CA$\mathrm{PEI} / \mathrm{UCV}$ en edades comprendidas entre 0 días y 1 mes de nacidos.

En cuanto a la ocupación de la madre, del total de neonatos investigados tenemos que el perfil ocupacional de las madres de los $\mathrm{VIH}(+)$ y de los VIH(-) verticalmente expuestos es aproximadamente igual; $71,9 \%$ de las madres de los $\mathrm{VIH}(+)$ y 77,8\% de las madres de los VIH(-) están ocupados en hogar (Tabla 1).

Los datos sobre la procedencia geográfica de los niños nos muestra, el 32,2\% (20) proceden del Interior y el 67,7\% (42) de los niños proceden de la Gran Caracas, categoría presentada por casi la totalidad de los VIH(-) fue de 57.1\%(24). Mientras que los $\mathrm{VIH}(+)$ de $42,8 \%$ (18) provienen de esta área. Siendo la mayoría de los neonatos procedentes de la Gran Caracas (Tabla 2).

Al analizar las variables sociodemográficas según el género se encontró un mayor número de varones $56,4 \%$ (35) que hembras 43,6\% (27) (Tabla 3).

El motivo de consulta más reportado fue el control en los niños VIH (-) expuestos con un $72,7 \%$ (24) y en los niños $\mathrm{VIH}(+)$ fue la consulta de emergencia con un $88 \%$ (22) Las diferencias encontradas alcanzaron significación estadística (c2 =9,7; p-valor =0,002) (Tabla 4).

Tabla 1. Distribución de acuerdo a la ocupación de la madre.

\begin{tabular}{|c|c|c|c|}
\hline Ocupación de la madre & VIH/SIDA & Expuestos & Total \\
\hline hogar & $23(71,9 \%)$ & $21(77,8 \%)$ & $44(74,6 \%)$ \\
\hline comerciante & $7(21,9 \%)$ & $6(22,2 \%)$ & $13(22,0 \%)$ \\
\hline otro & $2(6,3 \%)$ & - & $2(3,4 \%)$ \\
\hline
\end{tabular}

$X^{2}=1,75 p$ valor 0,42

Tabla 2. Distribución de neonatos clasificados según su procedencia.

\begin{tabular}{|c|c|c|c|}
\hline Procedencia & VIH/SIDA & Expuestos & Total \\
\hline Gran Caracas & $18(42,8 \%)$ & $24(57,1 \%)$ & $42(67,7 \%)$ \\
\hline Interior & $15(75 \%)$ & $5(25 \%)$ & $20(32,2 \%)$ \\
\hline
\end{tabular}

$X^{2}=8,84$ p valor 0,003 
Tabla 3. Distribución de neonatos de acuerdo al género.

\begin{tabular}{|c|c|c|c|}
\hline Sexo & VIH/SIDA & Expuestos & Total \\
\hline Varones & $21(60 \%)$ & $14(40 \%)$ & $35(56,4 \%)$ \\
\hline Hembras & $13(48,1 \%)$ & $14(51,8 \%)$ & $27(43,6 \%)$ \\
\hline
\end{tabular}

$X^{2}=1,15 p$ valor 0,28

Tabla 4. Distribución de neonatos de acuerdo al motivo de consulta

\begin{tabular}{|c|c|c|c|}
\hline Motivo de Consulta & VIH/sida & Expuestos & Total \\
\hline Emergencia & $22(88 \%)$ & $3(12 \%)$ & $25(40,3 \%)$ \\
\hline Control & $9(27,2 \%)$ & $24(72,7 \%)$ & $33(53,2 \%)$ \\
\hline Otro & $3(75 \%)$ & $1(25 \%)$ & $4(6,4 \%)$ \\
\hline
\end{tabular}

$X^{2}=3,7 p$ valor 0,54

Tabla 5. Distribución de acuerdo a la presencia de quistes de la lámina dental

\begin{tabular}{|c|c|c|c|}
\hline Quiste de la lámina dental & VIH/SIDA & Expuestos & Total \\
\hline No & $8(25,0 \%)$ & $6(7,4 \%)$ & $14(16,9 \%)$ \\
\hline $\mathrm{Si}$ & $24(75,0 \%)$ & $25(92,6 \%)$ & $49(83,1 \%)$ \\
\hline
\end{tabular}

$X^{2}=3,22$ valor 0,07 or $=4,2^{*}(N S)$

Tabla 6. Distribución de acuerdo a la localización de quistes

\begin{tabular}{|c|c|c|c|}
\hline Quistes de la lámina dental & VIH/SIDA & Expuestos & Total \\
\hline Paladar & $4(37,5 \%)$ & $7(25,9 \%)$ & $19(32,2 \%)$ \\
\hline reborde alveolar & $20(62,5 \%)$ & $23(74,1 \%)$ & $43(67,8 \%)$ \\
\hline
\end{tabular}

$X^{2}=0,90$ p valor 0,34 or $=1,71$ (NS)

De acuerdo a la presencia de quistes de la lámina dental, cabe destacar que el 83,1\% (49) presento quistes, por lo que debemos señalar que el $92,6 \%$ (25) son niños VIH(-) y el 75,0\% (24) son VIH(+) (Tabla 5).
Con respecto a la localización de los quistes de la lámina dental la más reportada fue en reborde alveolar con el 74,1\% (23) en niños VIH (-) y en los niños VIH (+) a nivel del paladar con un $37,5 \%$ (4) (Tabla 6). 
Tabla 7. Distribución de acuerdo a la presencia de quistes en el paladar

\begin{tabular}{|c|c|c|c|}
\hline Paladar & VIH/SIDA & Expuestos & Total \\
\hline Duro & $4(28,5 \%)$ & $6(42,8 \%)$ & $10(16,1 \%)$ \\
\hline Blando & - & $1(92,6 \%)$ & $1(1,6 \%)$ \\
\hline
\end{tabular}

$X^{2}=3,22$ valor 0,07 or $=4,2^{*}(\mathrm{NS})$

Los datos sobre la presencia de quistes de la lámina dental en el paladar nos muestra que el $1,6 \%$ (1) de los VIH(-) presentó en paladar blando como así mismo en dicho grupo el 42,8\% (6) se presentó en paladar duro, a diferencia de los niños $\mathrm{VIH}(+)$ el 28,5\% (4) se presentó en paladar duro (Tabla 7).

\section{Discusión}

Para la prevalencia de la transmisión vertical VIH(+), según el Ministerio de Salud y Desarrollo Social para el Poder Popular en el año 2009 confirmó otorgar gratuitamente las pruebas de anticuerpos contra el VIH con carácter obligatorio para toda embarazada que concurra a la consulta prenatal en centros públicos o privados ${ }^{28}$. En este trabajo se encontró oportunidades perdidas ya que los $32 \mathrm{VIH}(+)$ diagnosticados post parto a pesar de esta resolución.

La ocupación de la madre VIH/SIDA en este estudio arrojó que en su mayoría permanecen en sus casas $\sin$ recibir salario $74,6 \%$, corroborando la preocupación a nivel Nacional para el Ministerio de Salud y Desarrollo Social cuando hablan de las complejidades de la mujer VIH/ sida relacionadas con las limitaciones sociales, derechos legales y circunstancias económicas como perdida de ingreso, del Seguro Social y abandono de la pareja. Cabe destacar que ONUSIDA 1998 destacó que los reportes venezolanos evidenciaban un incremento de número de mujeres VIH/ sida eran amas de casa. ${ }^{28,29,30}$

En este trabajo se observó que la mayoría de los pacientes viven en la gran Caracas 67,7\%, pero todavía un porcentaje del interior del país se controla el VIH en Caracas pensamos que esto es debido al estigma social de la enfermedad que las lleva a ocultarla y controlarse lejos de sus casas. Lo que corrobora, lo reportado por la Dra Guerra en el 2006, quien en su estudio encontró que la mayoría de los pacientes $69 \%$ viven en la Gran Caracas. ${ }^{31,32,33}$

En relación al género en este estudio se encontró más afectado al masculino con 59,3\% mientras que el femenino con $40,7 \%$, al igual que en la literatura revisada está bien establecido que el sexo masculino en adultos se encuentra más afectado $^{9,10,11}$.

Al igual que lo reportado por Guerra y cols. $(2006)^{31}$ la emergencia fue motivo de consulta señalado con mayor frecuencia por los representantes de los $\mathrm{VIH}(+)$, ubicado en un $88 \%$ a diferencia de los niños VIH(-) expuestos que refirieron la consulta control en un $72,7 \%$.

Al igual que Aumaítre $2006^{9}$ con este trabajo coincidimos con Robinson \& Roberton (1996) citados por esta autora, tomando en cuenta los criterios diferentes de clasificación de categorías 
de los quistes en torno a su localización y forma específica de presentación en su tomo de Pediatría práctica. Ellos refieren que los nódulos de Bohn aparecen de manera predominante sobre la superficie externa de las crestas alveolares o margen gingival respectivamente. Existen otros nódulos similares, que se encuentran sobre la línea media del paladar y están formados de remanentes epiteliales, se les conoce como perlas de Epstein. Los quistes de la Lámina Dental suelen aparecer aislados, en el borde de la cresta alveolar. Lo único que coincide con nosotros es que son más frecuentes en los rebordes alveolares pero no como Nódulos de Bohn sino como Quistes de la Lámina dental; por lo que asumimos que esta clasificación es más anatómica que histogénica, quizás por su especialidad ${ }^{9}$.

Debido a la diferente etiología que tienen las lesiones en los rebordes alveolares y en el paladar, se establecerá la frecuencia con que estos se presentan de manera independiente unos de los otros y en forma conjunta en los maxilares y en el paladar. La razón de esta mayor frecuencia de los quistes de la Lámina dental en los rebordes alveolares se puede explicar porque en los maxilares de los fetos y en recién nacidos se están formando las yemas dentales que entre primarios y permanentes se encuentran en diferentes etapas del desarrollo, lo cual constituye el periodo más fértil para que queden restos epiteliales odontogénicos atrapados en el tejido conjuntivo que los rodea, en nuestra muestra analizada la mayoría estaba más frecuente en los rebordes alveolares de los maxilares, esto se debe a que, además de los quistes que se encuentran en los rebordes alveolares, derivados de los restos de Lámina dental son quizás porcentualmente mayores a los restos epiteliales encontrados en la unión del paladar por restos fisurales o por glándulas salivales si los comparáramos, y específicamen- te en el maxilar superior que en la mandíbula, quizás puede deberse a que en la mandíbula la Lámina dental iniciaría y completaría su proceso de reabsorción más tempranamente que la Lámina dental del maxilar superior, dando mayor oportunidad a la formación de quistes superiores criterio que compartimos con Uauy y col $(1980)^{21}$, y con opiniones de Sanders $(1979)^{20}$, Laskaris $(2001)^{24}$ a pesar de que ellos no reportan porcentajes en frecuencia, no obstante resaltan la frecuencia que los quistes provenientes de la Lámina dental, tienen una incidencia muy común, exclusiva en neonatos, con localización usualmente en la mucosa alveolar del maxilar superior más que en otras localizaciones a pesar de que tienen agrupados en una sola entidad patológica a los Nódulos de Bohn, Perlas de Epstein, microquistes gingivales y glándulas o Perlas de Serres no dan frecuencia específica, localizan con preferencia en los rebordes alveolares vestibulares o encía bucal, aunque algunos autores indican que son más comunes a los lados del rafe medio del paladar duro.

Al igual que lo reportado por Aumaítre (2006) en su estudio de 242 neonatos venezolanos sanos quien encontró con 1 solo caso de quiste con localización extramaxilar (úvula, pilar anterior, labio y lengua) respectivamente, nosotros encontramos 1 en paladar blando de los niños $\mathrm{VIH}$ $(+)$.

\section{Conclusiones}

Después de la revisión de la literatura, sigue habiendo diferencias en cuanto a nomenclatura y clasificación por localización por diferentes autores y que ésta ha sido cambiante a través de los años sobre los quistes bucales en recién nacidos.

La mayoría de las publicaciones citan a las Perlas de Epstein y Nódulos de Bohn, siendo muy 
escasa las publicaciones que usen la nomenclatura de Quistes de la Lámina dental.

Resaltamos que encontramos resultados similares a estudios anteriores en niños sanos realizados en Venezuela por la Doctora Andra Amautre.
Queda bien establecida la importancia del odontopediatra dentro del equipo interdisciplinario de salud para el manejo del neonato en especial los niños $\mathrm{VIH}(+)$ y el verticalmente expuesto así como la responsabilidad de mejorar la calidad de vida de estos niños.

\section{Referencias}

1.Velasco E; Odontoestomatología y SIDA un Enfoque Interdisciplinario, Gráficas Alga, SA Barcelona 2002

2. Seber GA. Multivariable Observations. New York: WILEY, 1984.

3.Sedano H Frecuent oral diseases in HIV positive and AIDS patient. http://www.dent.ucla.edu 1997 ( Consultada $12 / 10 / 12)$

4.Jane E; Roseló X. Manifestaciones clínicas odontoestomatológicas asociadas al SIDA Arch Odontoestomatol

5.Clotet B \& Ruiz L Valor de la carga vírica en el manejo de los pacientes con VIH. Pub.Of.SEISIDA; 7: 228 9: $499-506: 1996$

6.Porter SR; Luker J; Scully C; Kumar N; Lesiones Orales en pacientes expuestos a infección por VIH en el Reino Unido. Estudio de 10 años, Medicina Oral; 4: 455-469. 1999

7.Yeh CK; Fox PC \& Ship JA Oral defense mechanisme are impaired early I HIV-1 infected patients JAIDS 1988;1: 361-366

8.Cifuentes R, Javier. RECIEN NACIDO, CONCEPTO, RIESGO Y CLASIFICACION www.minsa.gob.ni/enfermeria.2005 (Consultada 12/10/12)

9.Aumaítre, Andra. Estudio Trabajo de asenso Epidemiologico de Quistes Bucales en Neonatos Venezolanos. 2006.

10.Parmelee, A.H., The mouth of newborn. Pediatr Clin North Am., 3: 847-858. http: / / scad.bireme.br 1956. ( Consultada $12 / 10 / 12)$

11.Hooley, J.R., The Infant's mouth J.A.D.A.J Am. Dent Assoc., Vol 75:95-103. July 1967.

12.Fromm, A.F., Epstein's Pearls, Bohn's Nodules and Inclusión- cisycyst of the oral cavity. Journal of Dentistry for Children., Vol XXXIV. Number 4:275-287, Jul 1967.

13.Anderson., W.A.D \& Scotti, T. Patologia Basica. Edit Interamericana, 5ta. Edit SAICI Argentina 1968.

14.Maher, W.P \& Swidle, B.S., Etiology and vascularization of dental lamina Cyst. Oral Surg., Vol 29 No4:590-597. April 1970

15.Sicher, Orban's Oral Histology and Embriology, Ed 6th , St. Louis. The C. V. Mosby company. 1966

16.Shafer, G. W; Hine, M; Levy, B., A Textbook of Oral Pathology $4^{\circ}$ edi. W.B. Sanders Company, Philadelphia. 1984.

17.Shafer, G. W; Hine, M; Levy, B., Tratado de Patología Bucal $4^{\circ}$ edit. Nueva Edit. Interamericana, S.A. México. 1986

18.Gorlin, R.J \& Goldman,H.R., Thoma Patologia Oral. P 487-493. Salvat Editores Venezolana S.A Madrid. 1973

19.Arnold, W.H., Location and Distribution of Epitelial Pearls and Tooth Buds in Human Fetuses with Cleft lip and PalateCraniofacial Journal. Vol 35, No 4. July 1998

20.Sanders, B. Pediatrics oral and Maxilofacial Surgery, pp 246-247 The C.V. Mosby Company, St. Louis. 1979

21.Uauy, E; Celis, A; Martines, A. Estudio Epidemiologico de los quistes de la mucosa bucal en recién nacidos. Rev Asoc Odont Argentina., Vol.68, No. 8:51-513. 1980.

22.Batsakis, J.G. Tumors of the head and Neck. Clinical and Pathological Considerations. The Williams \& Wilkins Company. $2^{\circ}$ Edition. 1980 .

23.Moreillon, M.C \& Schroedre, H.E., Numerical frecuency of epithelial abnormalities, particulary microkeratocyst, in the developing human oral mucosa. Oral Surg., Vol 53 No. 1:44-45. January 1982. 
24.Laskaris, G., Patologia de niños y adolescentes. $1^{\text {a }}$ Edic. Actualidades Medico-Odontologicas Latinoamericana, C.A Caracas-Venezuela. 2001.

25.Epstein Pearls Gingival Cyst of the Newborn www.henryfordhealth.org (Consultado 11/11/11)

26.Factsheet 44 Ciclo vital del VIH http: / / www.aidsmap.com/spanish/factsheets (Consultado 11/11/11)

27.Informe de la Organización Mundial de la Salud. VIH/SIDA. htt: / / www.ctv.es/USERS/fpardo/vihdat.htt (Consultado $11 / 11 / 11)$

28.Ministerio de Salud y Desarrollo Social para el Poder Popular; Compilación de politicas sobre VIH/SIDA 2009 http: / / observatoriovihycarceles.org (Consultado 11/11/11)

29.Resolución 292- MSDS, 7 de agosto de 2000,Gaceta Oficial No. 37.009, por la cual se instituyen las pruebas de anticuerpos contra el VIH con carácter obligatorio para toda embarazada que concurra a la consulta prenatal en centros públicos o privados. (Consultado $11 / 11 / 11$ )

30.Castillo L, Polanco L, Domínguez C. Bello N. Cuentas Nacionales en VIH/SIDA http: / / www.sidalac.org (Consultado $11 / 11 / 11)$

31.Guerra ME, Tovar V, Garrido E, Carvajal A. Lesiones bucales y estatus inmunológico en niños vih/sida. Acta odontol. venez, Caracas, v. 45, n. 2, 2007.

32. EL NACIONAL.COM La vida con el SIDA 2007

33. ONUSIDA 2006 “Informe sobre la epidemia mundial de SIDA 2006: Resumen de orientación” http: / / www.greenfacssor/es/sidaindex.htm.

Recibido: 08-01-2014

Aceptado:23-01-2014

Correspondencia: maria.guerra@ucv.ve 